\title{
The 'Abject' Single: Exploring the Gendered Experience of Singleness in Britain
}

\section{Authors' Names and Correspondence}

Corresponding Author:

Ai-Ling Lai (Dr.)

University of Leicester

School of Management

Ken Edward Room 525

University Road

Leicester, UK

LE1 7RH

Tel: +44(0) 116525646

Email: a.lai@le.ac.uk

Ming Lim (Dr.)

University of Leicester

School of Management

Ken Edward Room 529D

University Road

Leicester, UK

LE1 7RH

Tel: +44 (0) 1162525520

Email: m.lim@le.ac.uk

Matthew Higgins (Dr.)

University of Leicester

School of Management

Ken Edward Room 402

University Road

Leicester, UK

LE1 7RH

Tel: +44 (0) 1162525564

Email: m.higgins@1e.ac.uk 


\begin{abstract}
This paper explores the gendered experience of singleness in Britain through a theoretical and empirical understanding of the 'abject'. Drawing on the writings of Judith Butler, we argue that 'singleness' is culturally pathologised as an 'abject other', a liminal state which renders the legitimation of the 'single subject' unintelligible. Through 14 active interviews with British singles, we demonstrate how our participants negotiate their marginal status vis-à-vis the marketplace and the broader society that continue to uphold heterosexual partnership as a normative form of intimacy. Our data uncovers persistent and powerful stereotypes of how singles ought to organize their lives and conform both to social, as well as market-driven, pressures. We therefore highlight research gaps in the experience of singleness and critique the heteronormative framework that remains dominant, yet concealed, in gender research.

\section{Summary Statement of Contribution}

This paper advances a theoretical and empirical understanding of the neglected experience of singleness and how singles understand and negotiate their gendered subjectivities in a coupleoriented marketplace. Theoretically, we have enhanced understanding of how the concept of 'abjection' can be developed to expose the 'naturalisation' of heterosexual relationships as a legitimate practice. We argue that the marketplace remains politically vested in the institution of heteronormativity. Our empirical study contributes to the understanding of how the circulation of the heterosexual imaginary in the marketplace shapes the experience of singleness. Most notably, our findings reveal that the experience of singleness is structured along gendered lines: a statein which single women are 'visibly' subjected to the disciplinary power that produces their 'abject' status. While single men have seemingly averted the disciplinary gaze, on the other hand, we also show that their singleness remains tenuously tethered to the heteronormative framework.
\end{abstract}

Keywords: Single/Singleness, Gender, Abject, Heteronormativity, Family, Intimacy 


\section{The 'Abject' Single: Exploring the Gendered Experience of Singleness in Britain}

\section{Introduction}

To date, there is surprisingly little research exploring single consumers and their participation in the marketplace. In this paper we explore the gendered experience of singleness and how this is negotiated within a marketplace that continues to legitimise heterosexual relationships as a normative form of intimacy (Budgeon 2008). Yet, census data and national surveys consistently highlight the growth of the single population (Euromonitor 2012), with $51 \%$ of Britain's population registered as 'unmarried' in 2011 compared to 30\% in 2001 (ONS 2012). Meanwhile, Burnett (2007) calls for the need to realise the 'untapped' potential of the singles market, suggesting that there has been an oversight by both academics and marketers to understand the consumption experience of singles (Wortzel 1977). We argue that such an oversight mirrors broader marginalisation of 'singleness' as a troubled cultural category (Reynolds and Wetherell 2003) in which single individuals are stigmatised as the 'abject other' since they do not conform to the dominant heterogender arrangements (Budgeon 2008; Ingraham 1996).

According to Rich (1980), and reinforced more recently by Appleby (2013) and Martin (2009), the experience of singleness is overshadowed by compulsory heteronormativity - an ideological framework that institutionalises heterosexuality as a 'natural' sexual preference. Rich argues that such a framework implicitly sustains patriarchal capitalism by persistently espousing marriage (Roseneil and Budgeon 2004) and the nuclear family (Bryne 2003) as ideals, thereby preserving 'male fantasies about women, and male interest in controlling women, particularly in the realms of sexuality and motherhood' (Rich 1980, p.634). More 
recently, consumer researchers are beginning to recognise the tacit operations of the heteronormative framework, which have informed much of gender research in marketing (Kates 1999; Bristor and Fischer 1993; Catterall et al. 2005; Borgerson et al. 2006; Peñaloza 1994). By prioritising the 'family/couple' as a valuable unit of consumption (O'Malley and Prothero 2007), marketers have silenced those voices whose relational practices fall outside of the heteronormative framework (Wilkes 1995).

This paper, therefore, seeks to reinstate the muted voices of 'singles' (Hirschman 1993) through a theoretical and empirically informed understanding of their engagement with marketing and the marketplace. We consider the socio-historical conditions that engender the 'naturalisation' of heterosexuality as an obligatory practice (Butler 1993). In doing so, this paper advances the theorisation of gender from the vantage point of the 'abject single' by understanding the extent to which their marginality (1) problematizes heterosexual partnership as an 'innate' sexual practice and by considering (2) whether their 'abject' position provides an emancipatory space that can potentially challenge the legitimacy of the status quo. We argue that an understanding of the abject experience of singleness is important for marketing and consumption since it exposes how society and the marketplace are complicit in reproducing and concealing the heteronormative framework whereby 'couplehood is implicitly privileged over singlehood' (Kates 1999, p.33). While 'society' in our view denotes sets of relations between actors, the 'marketplace' structures those relations in ways that allow or disallow varying degrees of agency by those who live in and around it (Giddens 1986). As Butler (1993) argues, it is through the 'abject' that we can begin to rearticulate and reassert terms of cultural legitimacy that challenge heteronormative assumptions. 
In the following sections, we discuss the theorisation of the abject through a critical review of the work of Julia Kristeva and Judith Butler. We demonstrate how the marketplace conceals the marginalisation of single consumers through the fabrication of a 'heterosexual imaginary'which celebrates marriage and the nuclear family. Next, we discuss how stereotypes of singleness produce regulatory power that discipline the 'abject single' while simultaneously instantiating a sexual double standard that regulates the gendered experience of singleness. Through active interviewing (Holstein and Gubrium 1995), our study provides a discursive space for 'single' individuals to articulate and make sense of their intimate lives. To do this we present and analyse the narratives of 14 participants as they negotiate their experience of 'singleness' within a couple-oriented marketplace.

\section{The Abjection of Singles: Paternal Law and Compulsory Heterosexuality}

Butler (1993) argues that the exclusionary matrix that privileges the heterosexual subject depends on 'the production of a domain of abject beings, those who are not yet subject' (p.xiii) and thus 'do not appear properly gendered' (p.xvii). Heteronormativity reinforces a construction of singleness that is seemingly conjoined to moral questions over social dysfunction, loneliness and anomie (Tonkiss 2003; Tiryakian 1981). Those whose intimate lives do not conform to the heteronormative framework are subjected to economic, political and social sanctions, as exemplified by the fate of Eleanor Rigby, the spinster who died alone, childless and in poverty. Indeed, single individuals are often construed as deviant (Rich 1980; Sandfield and Percy 2003; Holden 2007), pathological (Reynolds and Wetherell 2003) and promiscuous (Gordon 1994). As Butler (1993) implies, the symbolic repercussion of assuming the abject position of singleness is that of 'terror' since such a position is culturally 'unintelligible' given the lack of symbolic resources that make possible the articulation of single experience. The 'abject' single is therefore emblematic of a breakdown 
in meaning - thereby posing as a formidable threat that destabilises the institution of marriage (Cherlin 2004).

In Powers of Horror: An Essay on Abjection, Kristeva (1982) explains that the 'abject' threatens the integrity of one's clean and proper self (that of being opposed to I) and 'disturbs identity, system, order' (p.4). The 'abject' is therefore a site of horror because it beseeches and challenges the subject and possesses the potential to dissolve the boundaries that give the subject meaning and stability. In the moment of 'abjection', we are gripped by a sense of 'uncanniness' (Kristeva 1982) in which the familiarity of our spatial and temporal anchorage of being-at-home-in-the-world is disrupted (Tyler 2009). 'Abjection' is therefore experienced as a liminal state of 'the in-between, the ambiguous, the composite' (Kristeva 1982, p.4). The 'abject' thus occupies the zone between 'being and non-being' (Tyler 2009) where it is neither a subject nor an object (Kristeva 1982).

Drawing on the psychoanalytic writings of Jacques Lacan, Kristeva contends that subjectivity can only emerge through the process of 'abjecting', which involves a radical exclusion of what is deemed 'Other' to the self - the most potent abjection being that of 'maternal abjection'. In reference to Lacan's theory of the mirror stage ${ }^{1}$ (1977), Kristeva explains that individuation is predicated on the (infant) 'subject' recognizing its individuality as being discontinuous from the womb of the 'mother'. In other words, the 'subject' is born of a violent abjection of the maternal body and thus establishing a border that separate the 'I' from the 'Other', the 'individual' from the 'social' body. The 'maternal body' is thus a monstrous body (Creed 1993) whose devouring potential threatens to engulf the self and

\footnotetext{
${ }^{1}$ The mirror stage is a psychoanalysis concept introduced by Lacan, who posits that the formation of the 'subject' is inaugurated when the infant recognises himself in the reflected image of the mirror as a unitary being, independent of others.
} 
erase the distinction between the 'I' and 'Other' (Tyler 2009). So as to maintain social order, the 'abject' and in particular the 'maternal body' must be domesticated through culture via the regulating authorities of religion, politics, morality and language (Cosivo 2004).

As such, culture is founded on the repression of the maternal drives - a state which Kristeva designates to the pre-discursive realm known as the Semiotic ${ }^{2}$, whilst culture is subsumed within the realm of the Symbolic ${ }^{3}$ (Butler 1990). This is a realm where the 'speaking subject' becomes acculturated into a signifying system made up of social conventions, codes of conduct, rules and regulations (Covino 2004). As Lacan argues, the Symbolic is structured by the Law of the Father and constitutes the universal principle that organises culture (Butler 1990). Kristeva calls for the revival of the Semiotic to subvert the Paternal Law.

This privileging of the 'maternal' Semiotic, however, is disputed by Butler (1990) as futile and essentialist. She argues that Kristeva has created a 'self-defeating' strategy since the Semiotic - given its pre-discursive nature - cannot be culturally sustained as a political practice. Instead, Butler (1990) contends that subversion can only be mobilised from within culture by exposing the mechanisms of its construction.

Through a Foucauldian reading, Butler (1990) argues that the psychoanalytic narrative of the maternal body as pre-discursive is, in itself, 'a product of a historically specific organisation

\footnotetext{
${ }^{2}$ The 'semiotic' is a pre-discursive domain where language is made up rhythm and movement - which is yet to be tainted by the symbolic representation of the paternal law. The semiotic is thus a realm of the 'abject', where maternal drives fuse the nurturing body of the mother to the future speaking subject. As such, the 'semiotic' world of the maternal is at once a place of nurturance for the 'subject-to-be' and a site of abjection that precondition the acquisition of symbolic 'language' (Covino 2004).

${ }^{3}$ The Symbolic is a concept inspired by Lacan, who claims that the individuation process occurs when the 'speaking subject' enters the world of language, governed by the Law of The Father. Kristeva finds Lacan's mother-free thesis problematic (Tyler 2009); arguing against the latter that 'abjection' begins in the Semiotic phase - a phase which precedes the entrance into the Symbolic (culture).
} 
of sexuality' (p.125). Such a narrative reifies motherhood as an 'innate maternal instinct' and is thus rendered compulsory for women. Developing a position with which we concur, Butler implies that the abjection of 'singleness' reflects the fantasy of a fearful heterosexist culture (1990) against the failure to sever the apron string of maternal dependency (Kristeva 1982).

Furthermore, Butler (1990) argues that the naturalisation of motherhood necessitates the cultivation of reproductive desires, which are institutionalised through heterosexual union and kinship. In other words, the regulatory norm of compulsory heterosexuality requires the propagation of bodies into discrete sexes with 'natural' heterosexual dispositions (Butler 1988). Underpinning this is the cultural imposition of exogamic heterosexuality, which mandates that sexual desires be directed towards the opposite sex, thus culminating in obligatory heterosexual marriage, a desire for procreation and the compulsion to establish a family (Rubin 1975). Singleness (alongside homosexuality) is deemed a violation of this exogamic arrangement.

Not only is heterosexuality presented as an 'innate' sexual preference, it also masks a deeper stratum of meaning - i.e. a society where couples - and couples only - enact socially acceptable norms and practices. According to Butler (1993), the legitimation of the 'heterosexual' subject is predicated on the regulation of phantasmatic identification, a process of identifying with a heterosexual position by 'fantasising the possibility of approximating that symbolic site' (p.61). In this way, heterosexual affiliation becomes legitimised as an unquestionable way of being - for whom one's 'humanness' as a gendered subject is rendered culturally intelligible and imaginable. At the same time, heteronormativity operates as a tacit exclusionary system by foreclosing the possibility of identifying with the abject 'single' - i.e. a position that is 'unthinkable' and 'difficult to imagine' (Butler 1988). This 
process of identification is cultivated through what Ingraham (1996) calls the 'heterosexual imaginary'. We will now discuss the complicity of marketing and consumer culture in maintaining this imaginary.

\section{The Heterosexual Imaginary in Marketing and Consumer Research}

Ingraham (1996) argues that the 'heterosexual imaginary' is produced to veil the sociohistorical conditions that construct heterosexuality as a 'natural' practice, thereby foreclosing the possibility of (critically) exposing heterosexuality as an organising institution. It is our contention that academic research in marketing and consumer research has contributed to the circulation of the 'heterosexual imaginary'. This is evident in the burgeoning body of work exploring (consumption) experiences of contemporary married women (Thompson et al. 1990), fathers (Bettany et al. 2014; Eräranta and Moisander 2011; Coskuner-Balli and Thompson 2012); working parents (Thompson 1996), single parents (Harrison et al. 2012) and mothers (Houston 2004; Carrigan and Szmigin 2010; 2006; Thomsen and Sørensen 2010; The Voice Group 2010). Heterosexuality is often celebrated through gift-giving rituals (Ingraham 1996; Sherry 1983) that valorise familial and romantic exchange of love (Belk and Coon 1993), dating experiences (Belk and Coon 1990), Valentine's Day (Otnes et al. 1994), Thanksgiving (Wallendoft and Arnould 1991) and Christmas (Fischer and Arnold 1990).

Indeed, cultural rituals such as weddings (Otnes and Pleck 2003), engagement (Fram and Baron 2004) and baby showers (Fischer and Gainer 1993) are tacit forms of heterosexual celebration, marking the normative rite of passage from singleness to marriage and parenthood. Similarly, theories of family life cycle in consumer research (e.g. Wells and Gubar 1966; Murphy and Staples 1979) typically espouse the developmental model (Wilkes 1995), which construe singleness as a temporary/preparatory phase prior to marriage (Holden 
2007). As Byrne (2003) and Carrigan and Szmigin (2994) observe, marriage and parenthood are considered important milestones of adulthood in Western culture. Hence, individuals who successfully attain such milestones are legitimised as 'moral' citizens (Gordon 1994) - who are productive, family-centred and more importantly appropriately (hetero)gendered. Meanwhile, individuals who remain single are deemed 'failed' subjects since they have not traversed the normative rite of passage as culturally 'expected' (Sandfield and Percy 2003).

Advertisers play a significant role in constructing the cultural imagery of the 'good life' (Catterall et al. 2005), which depicts sexual attraction between heterosexual couples (Schroeder and Borgerson 1998) and reinforces the idealised image of the nuclear family (Borgerson et al. 2006; Kates 1999). Leach (1968) coined the term 'the cereal packet family' to describe prominent media representations of a happy family - which is typically made up of a father (breadwinner), mother (usually a homemaker) and at least one child. These imageries engender the cultivation of 'desires', which as discussed above is implicitly orientated towards promoting the agenda of exogamic heterosexuality (Rubin 1975).

In recent years marketing practitioners and academics have started to embrace the plurality of family arrangements (Kerrane et al 2014), with examination of cohabitation, single parenthood, non-heterosexual partnerships and the stepfamily (Roseneil and Budgeon 2004; Stacey 1998). The incorporation of these variants through the idea of a 'postmodern family' (Houston 2004) is however admitted as approximates of the phantasmatic ideal of the traditional family (Butler 1993). For example, in their analysis of the gay family in advertisements, Borgerson et al. (2006) reveal how interpretive strategies such as gay window dressing and straightening up are employed by advertisers and consumers alike to impose heterosexual readings onto queer images. Similarly, Jackson and Scott (2004) observe that 
despite legal recognition of the 2004 Civil Partnership Act, all relationships (including homosexual partnership) have become 'heterosexualised' - i.e. tolerance of non-heterosexual partnership is recognized so long as conventions of family wholesomeness are upheld.

As we have outlined through these examples, the family is an important element of marketing theory and practice not only as a target of activities but also as a unit of consumption (O'Malley and Prothero 2007). Despite this, there has seemingly been no critique or deconstruction of the heteronormative institution of the family, or the implications of this assumption. The family, whether encompassing 'marriage' or not, is constituted of couples. This leaves singleness constructed through and positioned against representations of the family. In the next section, we consider how stereotypes of singleness are produced as a disciplinary practice to regulate the gendered experience of singleness.

\section{Singles, Stereotypes and Sexual Double Standard}

According to Rich (1980), industrial capitalism reinforces modernist dualisms by propagating gender inequality through the social division of labour. She contends that capitalism necessitates the participation of men in the public life of production, while women are relegated to the domestic life of reproduction (Hirschman 1993). Consumer researchers have long noted the enduring legacy of this gendered labour division, which they argue has ensured the perpetuation of the 'cult of domesticity' (e.g. Matcher 2013; Thompson 1996; Bristor and Fischer 1993).

In Women's Time (1981, p.31), Kristeva refutes the egalitarian agenda championed by firstwave feminism, claiming that 'the refusal of maternity (as a means to elevate Woman's position in public life) cannot be a mass policy and that the majority of women today see the 
possibility for fulfilment in bringing a child into the world'. She is equally critical of the second generation of feminists, who seek to reinstate women's position in a countersociety. Kristeva considers such a strategy to be a form of inverted sexism that can potentially elicit violence through the scapegoating of 'foreigners, other religion and the other sex' (p.27). Most notably, Kristeva regards the refusal of a paternal function by lesbian and single mothers as the most violent rejection of the Symbolic order, which she fears would lead to sexual anomie given that an alternative supplanting established social order is not in place. She therefore advocates a third way for women to embrace 'guiltless maternity' without compromising their professional life nor resort to a violent inversion of the Symbolic order.

However, as Thompson (1996) and Carrigan and Szmigin (2006) indicate, the 'cult of domesticity' remains an enduring presence in the aftermath of the feminist movement as contemporary mothers continue to experience guilt in their juggling lifestyle. Similarly, Eräranta and Moisander (2011) reveal that the egalitarian movement towards a more balanced and engaged form of parenting has yet to replace the discourse of 'manly fathering'. They posit that breadwinning has persisted as a significant constituent of male parenting since it coheres with being a good employee. Similarly, in their socio-historical analysis of advertisements in Good Housekeeping, Marshall et al (2014) suggest that the traditional models of paternal masculinity remain unchallenged despite the emergence of a hybrid form of masculinity that depicts the caring and latterly absent father. As such, Byrne (2003) argues that while men's identities are unencumbered by heterosexual attachments, women's identities remain strongly tied to their duties of care in their roles as mothers and wives.

Situated in this socio-political landscape, a woman who is unattached and childless raises tension (Gordon 1994) as her 'singleness' stands in contrast to the cultural construction of 
feminine virtues: which connote 'purity', 'piety', 'domesticity' and 'submissiveness' (Holden 2007). Spinsters, along with the image of the 'old maid', emerged as pathological stereotypes in the $19^{\text {th }}$ century to portray the undesirable state of 'unmarriageable daughters, aunts or sisters' (Gordon 1994), who were 'left on the shelf' due to their 'unattractiveness' (Holden 2007). These stereotypes are at odds with the phantasmatic ideal of womanhood, which render the spinster/old maid as 'not quite woman' (Butler 1993; Gordon 1994). The prospect of becoming a spinster/old maid therefore invokes 'terror' (Kristeva 1982) since women are unable to identify with this 'abject' position of singleness (Butler 1993) and thus feel compelled to seek fulfilment through marriage and motherhood (Byrne 2003).

However, Gordon (1994) argues that the stereotypes of the old maid/spinster are becoming obsolete as women gain greater financial independence. Women today are as likely as men to be breadwinners and can no longer be easily characterised as 'economically submissive' or 'downtrodden' (Holden 2007, p.54). This climate of 'choice' is ripe for the emergence of the 'city-single' stereotype, which portrays single women as career-minded, progressive, carefree and independent of men (Gordon 1994). However, Holden argues that these seemingly positive representations of single women are riddled with ambivalence especially in the years following the 1950s when increasing affluence and leisure have led to greater sexual availability of women outside of marriage. This is reflected in the now classic book, Sex and the Single Girl, in which Helen Gurley Brown (1962) candidly champions the ideas of open sexuality and of living a life of one's own. The 'city-single' provokes moral panic among social conservatives since it undermines male control over women's sexuality. More importantly, the 'city-single' poses a danger to the institution of marriage by unravelling the fabric of the family unit. This inflames cultural imaginaries of single women as 'femme 
fatale' and 'female predator' (Budgeon 2008) who are 'promiscuous', 'selfish' and 'hedonistic' (Gordon 1994).

There is however no direct equivalent to the abject stereotyping of male singleness. Bachelorhood is seen as a 'desirable' and 'normative' way of being for men (Budgeon 2008). As Holden (2007) suggests, a man is assumed to be 'always already single' as his identities are traditionally defined through capitalist production, which release him from domestic entanglements. Indeed, it is culturally held that marriage is a 'trap' for a man and that bachelorhood presents the 'intermediate' rite of passage for him to 'sow his wild oats' before assuming the role of a breadwinner (Holden 2007, p.8). In addition, the stereotype of the 'playboy' is often glamourised as carefree, hedonistic and seductive (Zayer et al. 2012). This sexual double standard exposes how gender inequality continues to shape the social regulation of single intimacies (Budgeon 2008; Holden 2007). Singleness is considered to be a 'choice' for the bachelor - who unlike the 'old maid/spinster' - retains the agency to shape his interpersonal life (Budgeon 2008).

However, Zajicek and Koski (2003) suggest that perpetual bachelorhood elicits suspicion as the unmarried state is deemed 'unnatural' (Budgeon 2008). According to Holden (2007), the cultural idealisation of motherhood meant that single men are left in a position of 'either having to reject maternal and family ties or be seen as mothers' boys who never grow up' (p9). Under Kristeva's terms, the bachelor is a 'failed' subject because he has not emerged from the liminal recesses of the 'abject' and is therefore deemed as 'not quite proper man.' 
The next section outlines our methodology for unpacking these contradictory images of singles and their myriad interactions within a marketplace and society that continues to be biased against singleness.

\section{Methodology}

In this study, active interviewing (Holstein and Gubrium, 1995) was conducted with 14 single adults aged 22-56 who currently reside in the UK. As this study aims to reinstate the 'muted' voices of single adults and their experience of the marketplace, participants were therefore selected based on what Mason (1996) calls 'sampling experiences.' This is to ensure that the participants chosen can relate meaningfully to the topic of interest (i.e. experience of singleness). As such, a snowballing technique is particularly useful and appropriate as a way to gain access to participants who are both information and experience-rich (Patton 1990). We approached our gatekeepers - which include friends, colleagues and organisers of two social groups (meetup.com ${ }^{4}$ ) - to recommend individuals they deemed would be suitable for this study. Our gatekeepers were briefed on the objectives of this study and were asked to connect us to individuals who 'identify' themselves as 'single'. This is important because we recognise that there is a need to be inclusive of a myriad of subjective positions that constitute the 'single category,' which include the 'never married', 'divorced/separated' and 'the single parents' (Budgeon 2008).

\footnotetext{
${ }^{4}$ Meetup.com is an online-facilitated social group, which organise offline social events and meetings based on common interest in various localities. Two group organisers based in Leicester and Nottingham were contacted for this study. These groups are approached due to their large portfolio of single adult members. Both groups attract members from a diversity of ethnic groups and occupational backgrounds. Both groups organise social events such as dining, cinema, pub meet, theatre etc. The first author is also a member of both meetup groups.
} 
In addition, we avoided privileging the voices of the hegemonic group by including participants from a diversity of gender, age, social classes and ethnic groups (see Appendix A). We did not intentionally exclude widows and gay/lesbian singles but the referral process did not yield any contacts. Similarly, we had been unable to identify unmarried single parents through our gatekeepers. While the latest statistics indicate that lone parent families make up $26 \%$ of the UK households and $51 \%$ of these parents had their children outside of marriage (ONS 2012), this group remains unforthcoming due to enduring stigma. According to Paton (2012), the historical stigma of single parents (especially women) having a child 'out of wedlock' remains evident in the current economic recession: cultural stereotypes of 'mothers on benefits,' 'welfare cheats' and 'scroungers' are widely circulated in the UK media creating a 'climate of fear' among 'unmarried parents' (Ramesh 2012). Our sampling criteria nevertheless espoused democratic participation, in keeping with the guidelines of active interviewing: thus, we include a 'wide range of voices, assigning narrative competence to all those placed in the category, recognizing their common worth as human beings and respondents' (Holstein and Gubrium 1995, p.25). Our participants were fully informed of the purpose and potential output of this research. In addition, participants were reassured that their participation was voluntary and the research data and any personally identifying information would be kept confidential. Pseudonyms were used to protect the anonymity and privacy of the participants. They also signed a consent form granting us permission to audiotape the interview.

In recognition of the need to make visible the invisible operations of heteronormativity, this study called for a participative and dialogical form of interviewing (Moisander et al. 2009). Active interviewing was employed for this study as it is a dynamic interpretive practice that involves the co-production and negotiation of meanings between the researcher and the 
participants (Holstein and Gubrium 1995). Here, the researcher interacts with the participants who actively draw on multiple interpretive resources of gendered knowledge, biographical particulars, cultural narratives and situated conditions to account for their experience of singleness. In doing so, both parties are able to confront the taken-for-granted norms of heterosexual familism and coupling (Byrne 2003). The participant is therefore 'always already' an active maker of meaning (Holstein and Gubrium 1995, p.9) who presents to the researcher different aspects of his/her (consumption) experiences, depending on the perspectival standpoint he/she occupies. In this study, participants often narrate from different vantage points by engaging in what Holstein and Gubrium call 'positional shifts'. For instance, single women were encouraged to orient their narrative from the standpoint of single men and vice versa, thus activating their stock of knowledge pertaining to gender stereotypes and to problematize and at times contest the regulative power that shapes their experience of singleness. Our participants were also encouraged to occupy different positions by 'walking in the shoes' of gay-straight singles, younger-older singles and the married-unmarried.

Active interviewing produces cultural talk (Moisander et al. 2009) that reveals the dynamic interplay between (1) the substantive content that emerges from the experience of singleness (what is assembled) and (2) the meaning making process involved in constructing and presenting an account of singleness (how it is assembled). In order to ease the intertextual linkage of these two domains, the NVivo software was utilised to code, retrieve, store, organize, consolidate and annotate emerging themes, hunches and discursive strategies from the interviews into manageable units of meaning. Our analysis is predicated on a close reading and detailed analysis of the performative capacity of language (Moisander and Valtonen 2006) to illuminate how participants employ linguistic properties to communicate and negotiate their substantive experiences (what). In this study, we analysed the way in which 
participants enact (1) explicit and implicit heterosexual norms to account for their 'outsider' status as singles, (2) cultural stereotypes of singleness to reveal underlying gender differences and power relations and (3) popular representations as interpretive resources that frame and substantiate their account of singleness.

\section{Analysis}

This section presents an in-depth analysis of 2 prominent themes. These reveal participants' (1) understanding and negotiation of being single in a heteronormative marketplace and (2) their active unravelling of the gendered construction of singleness. Almost all of the data presented in this section relate strongly, either directly or indirectly, to participants' clearsighted awareness that singleness was 'othered' by a dominant paradigm of heterosexual coupling that was both age and gender-sensitive.

\section{Re-Thinking the Good Life: On Being Single in a Heteronormative Marketplace}

The participants in this study constantly encounter situations where they have to account for their single status (Holden 2007). As Butler (1993) argues, heteronormativity produces 'singleness' as a domain of the abject, and consequently requires those who inhabit this position to justify their 'outsider' status as part of their identity construction (Budgeon 2008). Participants often speak of the tacit Symbolic law (Kristeva 1982) that governs the way in which they are expected to organise their interpersonal lives, as Arjun explains below:

'If you are part of the conventional (heterosexual) orientation then these social rules do apply to you and people would always like to know why you are single and living alone, you know 'get yourself a girlfriend', that kind of pressure.... Single in my twenties all the way up to 30 has been no pressure whatsoever. You don't feel people saying "are you with someone?" or anything like that because at that stage you are in those transient relationships anyway. From the age of 30 people start expecting you to settle down. It is like a conveyor belt of getting a house, moving in; 
getting married, having children you know and people want to know where you are...

I think to go through life and not get married you are missing out on something.

It is an institution isn't it?' (Arjun, Indian, Never Married, 40s)

Here, Arjun positions his subjectivity within the heterosexual conventionwhich predisposes him to the social rules (Paternal Law) that uphold the institution of marriage. For Arjun heteronormativity produces regulatory power (pressure) that is diffused through a network of micropolitical surveillance (people would always like to know why you are single) akin to Foucault's concept of the 'panoptic' gaze (1975). Indeed, singleness is perceived to be a transitory stage (Holden 2007) confined to the youthful age of 20-30 after which one is expected to settle down. Speaking from a male's perspective, Arjun considers singleness to be an unproblematic phase for a man in his 20 s since he is likely to indulge in transient relationships before assuming adult responsibilities (Holden 2007). This rite of passage into adulthood (Sandfield and Percy 2003) is encapsulated through the metaphor of the 'conveyor belt', which connotes a developmental yet predictable life cycle (Wilkes 1995) - i.e. from singlehood to 'getting a house, moving in; getting married and having children'. Keenly aware of such a regulative norm, Arjun is unable to imagine going through life as an unmarried man since it entails occupying an abject position that excludes him from the institution of marriage. The unmarried life is poignantly depicted as incomplete (missing out on something), the ambiguous 'something' points to the 'uncanniness' (Kristeva 1982) when one inhabits an unfamiliar zone outside of the established order (Tyler 2009). Thus, to be 'single' is to be in a liminal state (Kristeva 1982), where the 'self' emerges as a 'failed' gendered subject (Butler 1988), as Ingrid's narrative indicates below:

'I think the whole thing about Christmas... Because there's such a pressure to be happy and with your family and this idea of happy families and if you haven't got one, it makes you feel you're not good enough. I hate that pressure, I hate that expectation. I feel like when I'm with my mum and I haven't got a partner with me, or kids, and it's Christmas, it makes me feel like I'm still a kid and I haven't grown up. It makes me feel like I'm not a proper woman. Erm, (sigh) just all the advertising, the buying of presents, the advertisements for presents and who they're for, your 
man, your girlfriend, your kids. All the shopping and the food commercials always depict a big, happy family and yeah, it's rammed down your throat.' (Ingrid, White, Never Married, 40s)

For Ingrid, Christmas represents a ritual of heterosexual celebration (Ingraham 1996)which is epitomized by the happy gathering of families. In particular, advertising and Christmas giftshopping (Fischer and Arnold 1990) accentuate the heterosexual imaginary of the 'big happy family'. Ingrid is unable to identify with this since it admits only imageries of couples and children that approximate the phantasmatic ideal of the nuclear family (Kates 1999). For Ingrid, such ubiquitous representations of the heterosexual family are suffocating (rammed down your throat) and create an expectation that pressurises her to conform to the heteronormative framework while also acting as an admonition of her single status (not good enough). Ingrid's experience reflects the cultural imposition of 'compulsory maternity' on women (Butler 1990; Kristeva 1982). Here, Ingrid's singleness calls into question her cultural legitimacy as a mature subject (haven't grown up) since it implies her failure to embrace motherhood (Byrne 2003), thereby rendering her inappropriately gendered (not a proper woman). Like Ingrid, our participants hold the advertisers responsible for fabricating the imagery of the 'good life' (Catterell et al. 2005), as Arjun explains below:

'I don't know if you know the (BBC) programme The Good Life. A couple living next door to each other, like an idyllic lifestyle. It is always like hunky dory you know. Everything is fine but you know with single people it is just not depicted in the same way....Advertisers know of a demographic, which is families...I think previously there was perhaps more households as families so they were aimed towards them...like (the) Bisto Gravy (advert)....It is all catered about family life, you know two kids, one boy and one girl, mum and dad like conventional kind of British family.. You know there is not a single parent; there are two married people with their two kids tucking into some food. That is a stereotypical family, middle class. The cereal packet family. Other than that I have not seen any tailored towards single people.' (Arjun, Indian, Never Married, 40s)

Arjun remarks that advertisers and popular culture tend to portray images that predominantly reflect traditional family values. He refers to the BBC sitcom 'The Good Life' as exemplary of family wholesomeness (Kates 1999), which he describes as 'idyllic' and 'hunky dory'. 
Arjun demonstrates how the stereotype of the 'cereal packet family' (Leach 1968) is encapsulated through the Bisto gravy advert, which depicts married couples and children as signifiers of a conventional British family. In doing so, Arjun implies that the advertiser is able to resonate with politically privileged consumers who are typically white and middle class. For Arjun, the exclusion of single people in advertisement renders them invisible as a valuable unit of consumption (Wilkes 1995). Other participants describe their experience of the marketplace as not only exclusionary but discriminatory, as Javinder indicates below:

'I can only see two types of attitudes towards single people. There are those who want to make money out of us and those who are oblivious that we are single. You have got businesses who think 'single person, 'let's charge them more money' and they make money out of us. One way or another you seem to be always at a loss aren't you being a single person either financially or emotionally. Going back to what we said earlier with the hotels you have to pay single supplement which annoys me. Why do I have to pay extra because there is one less person going? It still seems to be unfair that I'm being penalised for being single. I mean a couple of times I've been for long weekends in London and I've paid the single supplement....As a global company... it will always market towards the family and (until) the world could be totally single, that is when it would change.' (Javinder, Indian, Divorced/Annulment, 40s)

Like Arjun, Javinder asserts that single consumers are often treated as an 'oblivious' unit by businesses. Her narrative reveals her sense of disempowerment by the market (always at a loss), which will always cater towards the family. In other words, the family unit is prioritised as an essential target for marketers (O’Malley and Prothero 2007) while the singles market remains 'untapped' (Burnett 2007). Javinder postulates that it is only through increased visibility of collective singleness that marketers can begin to realise the potential of the singles market.

In addition, Javinder's sense of alienation is compounded by exploitative marketing practices (make money out of us), which she considers to be discriminative against single consumers. She criticises the way in which single people have been 'unfairly' treated as 'second class' 
consumers (Goodwin and Lockshin 1992). In particular, Javinder expresses her annoyance against the policy of single supplement, protesting that she should not be made to 'pay extra' since this constitutes a persecution against single people (penalised for being single). In sum, our participants experience the marketplace as an exclusionary and discriminatory space that continues to privilege heterosexual couples and families. However, their marginalised experience of singleness is often structured by gender politics, which we will discuss in the following theme.

\section{Gendered Experience of Singleness}

Our participants' narratives reveal a gendered experience of singleness, which overtly pathologise single women while the single status of men remains shrouded in ambivalence. While there is a general recognition that society is moving towards an egalitarian organisation of intimate lives, our participants maintain that there is a 'sexual double standard' (Holden 2007) that continues to discipline women's singleness, as Annie reflects below:

'I'm the sort of person who doesn't feel like I'm going to settle down any time soon, ever. I would describe myself as a single butterfly, sort of alights here, alights there and doesn't like the idea of staying anywhere. To me being single means being unaccountable (to anyone else). Singlehood. It seems almost old fashioned so I would think more spinsters, the suffix "hood". So singlehood seems to me a lonely word, a bit of a sitting in your cottage wishing you had some children around you. Singleness, it seems almost abstract, almost like it pertains to an object rather than a person. I would say it's almost the default position for me, is to be single, because I'm a very independent person. I think at a very fundamental level a lot of people feel that it's not quite right. Especially when you pass a certain age I think it's very likely when you hear of a single woman over say 35 described, they say "oh she's gagging for a man, or she's desperate for a man" by which they mean she's single.... Yes. I would say women have a bit of the short end of the stick about it insofar as people will say "she's desperate for man", whereas a man is more likely to be described as you know "carefree bachelor."...I think a woman who is determined not to be matched up or who so to speak is past her peak or past her sell by date would be considered a pitiable object by the marketplace as well as by popular culture.'(Annie, White, Never Married, 30s) 
Unlike most participants in this study, Annie openly embraces her single status and describes herself as a single butterfly - a free-floating form of intimacy akin to Giddens' concept of confluent love (1992). For Annie, singleness involves making a resolute choice to live a life of independence (Beck and Beck-Gernsheim 2002). She describes her single status by using the term 'singleness' - which is an abstract construct free from cultural baggage.

In contrast, the suffix underlying 'singlehood' refers to the 'person' whose single identity is culturally loaded with negative connotations (Budgeon 2008). The term 'singlehood' is reminiscent of the stereotype of the spinster (Holden 2007), who 'sits in the cottage' longing for the presence of children. Spinsterhood becomes a concentrated site of derision against single women, whose childlessness constitutes a pathological lack (Kristeva 1982) against the cultural sanction for compulsory maternity (Butler 1990; Rubin 1975). To dissociate herself from the 'abject' representation of spinster(single)hood, Annie employs the term 'singleness' in an attempt to neutralise the 'pathological' connotations of the unmarried state (Holden 2007). In doing so, Annie potentially reinstates the cultural legitimacy of singleness as being on equal footing with marriage (Butler 1993).

Annie's resolute choice to remain single is analogous to the 'city-single' stereotype (Gordon 1994). Although apparently emancipatory and a far cry from the old-fashioned quiet life of desperation and loneliness faced by singles, the tacit norms of heterosexuality are still at work to ensure women's position remain fundamentally subordinated to male control (Rich 1980 ) and Annie is mindful of this. Thus, a woman who is determined to remain unmarried is cast as a sexual pariah (gagging/desperate for a man) since her independence is seen as a threat to the patriarchal institution of marriage (Cherlin 2004). They are pitiable objects who have passed their 'peaks' or 'sell-by-dates'. As discussed, this prejudice is compounded by 
cultural sanctions against childlessness (Byrne 2003; Butler 1990) in which older single women are perceived to be reproductively challenged, unlike the eternally fecund bachelor (who can afford to be carefree). As Annie observes, the marketplace and popular culture also play a significant role in reinforcing gender inequality and stereotypes of singleness (Zayer et al. 2012), a view also shared by Carlos:

'I mean you see like George Clooney or Al Pacino or ... some movie stars, people say "ok being single is nice". Of course people with lots of money can find many ideal mates but a man could get married by the age of $\mathbf{4 0}$ or $\mathbf{4 2}$ and he has kids and he's still considered someone who's got a long time ahead for his career and raise the kids. At the end of the day he's considered as an experienced and conscientious person who has fun, spent 20 years of his life meeting many girlfriends or whatever and then he is prepared to move towards sharing his life with someone else.' (Carlos, Greek, Never Married, 30s)

Like Annie, Carlos considers bachelorhood as 'carefree' and 'nice'. For Carlos, celebrities such as George Clooney and Al Pacino embody the quintessential bachelor, whose wealth ensures that they are presented with many options of finding their ideal mates. Unconstrained by the social pressure to marry, the bachelor is able to satisfy his sexual appetite by meeting many girlfriends (Holden 2007). Instead of being perceived as promiscuous, his sexual encounters are typically venerated as 'experienced' and 'fun'. As Carlos' narrative alludes, a man is always already single since marriage and fatherhood do not necessarily curb his freedom for he still has 'a long time ahead' to realise his roles as a producer (career) and a provider (raising kids). In the excerpt below, Ingrid shares her frustration as a working single woman whose career strips her of cultural resources that support her hard-won independence:

'I'm aware that for a single guy it's more permissible to be a kind of confirmed bachelor. All those stereotypes, confirmed bachelor or a bit of a player. Yeah, that's his choice to not marry. It is acceptable. If you're a woman, it's not a choice any woman would want but it's just put on them. It's tough luck if you're on your own, rather than a positive choice. You know, you can be single and happy and not need a guy and be enough on your own. And I think it really all stems back to that thing about identity. It's fine for a man to be a careerist, you know, have a career. But a woman is bound up in that identity...being, erm, er, a mother or you know, a homemaker. My bugbear is (if you are a) single woman, is crazy cat lady (laughter). I 
get annoyed because I'm aware of this stereotype.... I think it's derogatory towards women. It's, it's a bit of a put down. There must be something wrong with you if you're single and of a certain age and a female. Therefore you, you are very needy, erm, your cat is your child that you couldn't have or don't have. Whereas I don't think men are kind of tied down to these derogatory kind of stereotypes. I think you're seen as quite an oddity.... if you've not had children. I think it's not questioned as much if a man is childless... I think women are just as guilty of placing that expectation on other women as well. In fact I think it comes more strongly from women. I think that, that, um, that intrinsic core belief about roles and identity still prevails. And that men are the breadwinners and it hasn't shifted enough yet for parenting to be looked, to be seen as the kind of core responsibility of the man.' (Ingrid, 40s, White British, Never Married)

In the narrative above, Ingrid despises the derogatory stereotypes aimed at single women, which she perceives to be ' $a$ bit of a put down' that dampen women's accomplishments. Unlike Annie (single-by-choice), Ingrid discloses that it was not her choice to be single. Although she has embraced singleness as an affirmative way of living (Stein 1975), she is clearly unhappy with the lack of emancipative space wherein single women can make a 'positive' choice to lead a 'happy' and 'complete' life of their own (Holden 2007). Ingrid postulates that this is attributed to the social condition in which gender identities are constructed in accordance to the social division of labour (Hirschman 1993).

Ingrid observes that women's identities are socially bound up with her domestic duties as homemakers and mothers (Byrne 2003). As a childless woman, Ingrid is made to feel like an 'oddity', which denotes that there is something 'wrong' with her. Remarkably, Ingrid is disheartened that women have collectively played a complicit role in perpetuating this stigmatisation (Holden 2007), further illustrating the tacit operations of heteronormative power. While the stereotype of the spinster has fallen out of popular use, it has nevertheless been replaced by the stereotype of the 'crazy cat lady', a 'flawed' woman whose failure to reproduce renders her eccentric (crazy) and in need of a surrogate child. The stereotype of the 'crazy cat lady' exerts its disciplinary power by turning the unfulfilled 'desire' for children 
into a pathologically displaced obsession (for cats) so as to placate single women's 'innate maternal instinct' (Kristeva 1982).

In contrast to the woman's lot, a man's identities are tied to the public sphere where he is free to pursue his career. Ingrid's narrative resonates with the analysis by Eräranta and Moisander (2011) stating that men's role as breadwinners have exempted them from the responsibility of fatherhood despite a shift towards egalitarian parenting. While the stereotype of the carefree bachelor is prevalent in our interviews, however, the lived experience of singleness is not completely devoid of stigma for our male participants, as James indicates below:

'I've got some older friends... in their mid-40s for example and you do think just whether that is right. And to me it seems kind of sad... it's almost like being stuck in a rut without realising it...with phrases like "lonely old man" and...that really does seem depressing because I don't think we're meant to be on our own. We're social animals, I think, you know, we thrive off living vicariously, or living from other people's experiences and being fulfilled. So, that kind of unnerved me a little bit actually. You're sitting there with your baked beans and that's it. And then you're in a bar and I'm with some friends and you can see like an old chap standing at the bar having a pint, and I say to my friends "you see that guy over there, I hope that's not me coming to the same bar, the same Thursday every week for the next 30 years, that would be absolutely soul destroying, that would be just nightmarish." (James, 30s, White British, Never Married)

James' narrative reveals how heteronormativity has tacitly constructed perpetual singleness as 'unnatural' - it is not right (Zajicek and Koski 2003). Here, James asserts that man is inherently a 'social animal' and is therefore 'not meant to be on their own'. The thought of leading a life of perpetual bachelorhood evokes an abject sense of 'horror' (Kristeva 1982), which James describes as unnerving, sad and depressing. The 'lonely old man' leads a 'nightmarish' and 'soul destroying' life' as he is 'stuck in the rut' of a banal routine of consumption. The 'baked beans' and the 'pint' are symbols of loneliness, which intensify the stigmatized experience of singleness (Goodwin and Lockshin 1992). Similarly, Arjun's perpetual bachelorhood has also been called into question as the excerpt below indicates: 
'With guys, people mainly perceive the guy to either be a bit of a Romeo and can't settle down with one girl so he is gadding about left, right and centre with many women or like a polarity, the other people may assume, oh he is gay then. Strange. I think there is that certain assumption that oh he is not married because he is gay. Nobody is blatantly saying that to me but certainly when I used to speak to my father about it he used to say "I think you should get married otherwise people will think you are gay."' (Arjun, 40s, Indian, Never Married)

Arjun observes that there is a polarity in how society perceives male singleness. While the bachelor has been commonly glamourised as a player (a bit of a Romeo), failure to settle down nevertheless elicits social tension. Arjun recalls a conversation with his father, in which his unmarried state raises question concerning his sexuality (people will think you are gay). The bachelor - like the gay man - is emblematic of a man's failure to attain 'maternal abjection' (Kristeva 1982). His father's admonition demonstrates how bachelorhood has been culturally reworked as the 'delegitimised' sex since it fails to approximate the normative phantasm of compulsory heterosexuality (Rich 1980; Butler 1993). In sum, our analysis reveals a gendered structuring of single experience, which has reinforced the patriarchal organisation of labour division. Heteronormativity imposes a sexual double standard that continues to marginalise women's singleness. Men however are caught in a double bind as their singleness while celebrated also constitutes a site that accentuates their pathology.

\section{Discussion}

This study has set out to explore the neglected and often 'unspoken' experience of singleness and the consumption context in which it is embedded. Our participants' narratives unmask deep-seated social, political, economic and historical forces that condition the biographical construction of single lives. Our findings reveal enduring cultural stereotypes and practices, which are continuously enacted in popular media, cultural rituals as well as marketplace activities, and thus, constitute the exclusionary matrix that produces the 'abject' single (Butler 1993). 
Our empirical data shows clearly that what Kristeva (1982) has called the 'abject' operates as powerfully in singlehood as it does in the much more widely-cited and established scholarship on motherhood and parenting. Our paper therefore extends the conceptualisation of 'abjection' through the exploration of singleness - which as our participants' narratives show - is experienced as an 'uncanny' sense of social and psychic isolation and unfolds as a force through social networks of relations, markets, public and private spaces. As Butler (1993) argues, the domain of the 'abject' is culturally unintelligible and 'uninhabitable'. Singleness, we propose, is thus an enactment of abjection, 'acted out' both 'within 'us' and within 'culture' (Tyler 2009). Following Butler (1993; 1988), we argue that this 'acting out' of abjection is a 'performative' reiteration of the heterosexual norms, which over time come to be experienced as 'natural' and 'compulsory' (Rich 1980). Our participants are thus conditioned by this heteronormative framework, which 'pathologises' them as 'failed subjects' and by implication, they are 'inappropriately gendered'.

In occupying a marginalised space, our participants are mindful of being positioned against a culture that institutionalises heterosexual relationships and parenthood as 'natural' practices. Whether single-by-default - i.e. a state into which one is 'thrown' and therefore has to cope with - or single by reflexive choice (e.g. Annie, Carlos, Jess), our participants found themselves devoid of cultural and interpretive resources that support their experience of singleness. For our participants, singleness is a transitory state of being, in which their legitimacy as a cultural 'subject' is perpetually suspended in a liminal space while precariously tethered to the heteronormative ideals (Kristeva 1982). Unable to claim cultural legitimacy, many of our participants internalise this cultural imposition of heteronormativity, claiming that (prolonged) singleness is 'unnatural' and 'unthinkable' as a long-term prospect. 
This process of 'internalisation' is exacerbated by their sense of being under the constant surveillance of the 'panoptic' gaze (Foucault 1975). In Foucauldian terms, our participants are conscious of their 'visibility' as 'delegitimised' subjects and thus become mired in the regulative norm that defines them as the bearer of the 'abject' (ibid. 1975: p.200). As our findings show, the participants in this study found themselves having to constantly account for their single status (Budgeon 2008), indicating that the disciplinary powers that govern sexual desires (Rubin 1975) are infiltrated through the micropolitical capilary of everyday life (Foucault 1975).

For our participants, the marketplace constitutes a potent site where such disciplinary powers are mobilised through market mechanisms (such as single supplement, 2-for-1 promotion) that largely exclude and 'penalise' them as 'singles' (Foucault 1975). Most notably, our participants perceive the marketplace to be a network that facilitates the circulation of the 'heterosexual imaginary' (Ingraham 1996), which ubiquitously celebrates 'the good life' of coupledom and traditional family. Consequently, they feel alienated by these marketmediated representations since they are unable to identify and approximate its symbolic site (Butler 1993). Consequently, our participants feel that their singleness has rendered them 'invisible' as a unit of consumption. While our participants call for the mobilisation of single collectives to raise visibility and cultural legitimacy (Coskuner-Balli and Thompson 2012), the demographic facts that the single population constitutes $51 \%$ of Britain's population (ONS 2012) suggest that the singles market is hardly a minority. Rather our study suggests that the neglect of the singles market is politically vested in the institution of heteronormativity. By targeting conventional couples and families, marketers can ensure the political correctness of their practices while tapping into the phantasmatic ideals that cultivate desire and aspiration for heterosexual coupling. Against this prevailing system of 
‘compulsory heterosexuality' (Rich 1980), single individual suffers a kind of reflexive and doubly wounding loss of cultural and social legitimacy - she/he is alternately rendered obscure and exploited by the marketplace.

Another fascinating insight afforded to gender theory by our data is the way in which participants describe their sense of 'disempowerment' against prevailing stigmas of singleness - as exemplified by stereotypes such as 'the spinster', 'the crazy cat lady', 'the sexual pariah', 'the lonely old man' and 'the gay bachelor'. These stereotypes were profoundly felt by participants to be far more damaging to single women than single men. The 'panoptic' gaze (Foucault 1975) that governs the stigmatisation of singleness is thus profoundly gendered. As our findings reveal, cultural stereotypes such as 'spinster' and 'the crazy cat lady' overtly discipline the single status of women since it reflects the regulative power of the Paternal Law that continues to subordinate women in relation to men. This stigmatisation is further compounded for women who are childless, as motherhood is culturally glorified as the sacred duty for women. Meanwhile, our male participants, while acknowledging the relative agency accorded to them through the stereotype of the bachelor, nevertheless reveal a problematic and lonely existence. Perpetual bachelorhood evokes ambivalence surrounding the homosexual tendency of single men, since the heteronormative framework necessitates the coming together of two discrete sexes (Butler 1988). As such, our male participants are rendered 'impotent' in the onslaught of heteronormative discourse.

Yet, our analysis also reveals how participants (e.g. Annie, Ingrid, Javinder and Arjun) actively employ discursive strategies to 'denaturalise' the heteronormative framework. By employing 'neutral' descriptors (e.g. singleness instead of singlehood; Ms. instead of Miss), our participants seek to diffuse the cultural baggage surrounding singleness and thus reclaim 
their subjectivity as being on equal terms with those who are married. Discursive strategies such as (a) offensive rhetoric (e.g. it's derogatory to women), (b) othering (they make money out of $\underline{u s}$ ) and (c) stating the obvious (e.g. it's an institution isn't it?) are also evident in our participants' narratives - through which they interrogate the taken-for-granted assumptions about compulsory heterosexuality and expose the cultural conditions and stereotypes that sustain it. Subversion is thus made possible by their participation in culture, albeit in a tenuous manner (Butler 1990).

\section{Conclusion}

Our research was triggered by the lack of nuanced understanding, in our view, of how singles experience the marketplace. We noted at the start of our paper that the theory of 'abjection' offers intriguing insighst for how research into singles greatly enriches mainstream gender studies in ways as yet unexplored by marketing researchers. We therefore set out to understand how single individuals negotiate their marginalized status in relation to the heteronormative framework that structures the marketplace and, on this basis, to begin actively unravelling the gendered construction of singleness.

Our findings contribute to gender research by reinstating the voices of singles, whose experience and marketplace engagement has been obscured by the privileging of heterosexual coupledom and family. We suggest that marketers need to broaden their perspective to embrace the potential of the singles market beyond offering the token 'singles supplement' or 'solo holidays'. Given the lack of interpretive resources available, marketers can resonate with this group by circulating market-mediated imagery and product/service offerings that celebrate singleness as a way of life and in doing so provide an emancipatory enclave where single consumers can carve out their significance within a couple-oriented marketplace. 
In addition, our findings reveal gender stratification in the experience of singleness, further exposing the prevalence of social division of labour in the organization of intimate lives. The gendered constructions of male/female singleness in different sectors- education, hospitality, housing, taxation, finances, leisure and so on - remains to be studied for their likely and actual impact on marketplace exclusion/inclusion as well as policy implications. Moreover, future research can contribute to knowledge by addressing the experience of singleness in the workplace and how this is negotiated within existing codes of conduct and normative frameworks related to career advancement and equality. In addition, contributions can also be made by expanding the research on childlessness, and incorporating a focus on homosexuality. For example, future research can explore how the growing phenomenon of the childfree movement challenges the heteronormative framework that valorises parenthood. As we have indicated in our discussion of our sample, further field work is also necessary to incorporate the voices of gay/lesbian and asexual singles to gauge how their perceptions and experiences of singleness might challenge orthodox pressures of heteronormativity. By bringing these experiences to the fore, our research and future studies could provide a stepping stone for singles to reflect on, and potentially rewrite, their interpersonal history and, in doing so,reclaim cultural legitimacy as gendered subjects. 


\section{REFERENCES}

Appleby, R. (2013) Singleness, Marriage, and the Construction of Heterosexual Masculinities: Australian Men Teaching English in Japan. Portal Journal of Multidisciplinary International Studies, Vol. 10(1), 1-21. doi: http://dx.doi.org/10.5130/portal.v10i1.2334

Beck, U. \& Beck-Gernsheim, E. (2002). Individualization: Institutionalized Individualism and its Social and Political, London, Sage.

Belk, R.W. \& Coon, G.S. (1990). Can't Buy Me Love: Dating, Money, and Gifts, in R.H. Holman and M.R. Solomon (eds.) Advances in Consumer Research, Vol.18, Provo, UT: Association for Consumer Research, 521-527.

Belk, R.W. \& Coon, G.S. (1993). Gift Giving as Agapic Love: An Alternative to the Exchange Paradigm Based on Dating Experiences, Journal of Consumer Research. Vol. 20(3), 393-417. doi: http://www.jstor.org/stable/2489355

Bettany, S., Kerrane, B. \& Hogg, M. (2014). The Material-Semiotics of Fatherhood: The Coemergence of Technology and Contemporary Fatherhood. Journal of Business Research, Vol. 67(7), 1544-1551. doi:10.1016/j.jbusres.2014.01.012

Borgerson, J. L., Schroeder, J. E., Blomberg, B. \& Thorssén, E. (2006). The Gay Family in the Ad: Consumer Responses to Non-traditional Families in Marketing Communications. Journal of Marketing Management, Vol. 22(9-10), 955-978. doi:10.1362/026725706778935646

Bristor, J. M., \& Fischer, E. (1993). Feminist Thought: Implications for Consumer Research. Journal of Consumer Research, Vol. 19(4), 518-536. doi:http://www.jstor.org/stable/2489438

Brown, H.G. (1962). Sex and the Single Girl. New York: Barricade Books Inc.

Budgeon, S. (2008), Couple Culture and the Production of Singleness, Sexualities, Vol. 11(3), 301-325. doi: 10.1177/1363460708089422

Burnett, J.J. (2007). Adult Singles: An Untapped Market. International Journal of Bank Marketing, Vol. 8(4), 10-16. doi:10.1108/02652329010136217

Butler, J. (1988). Performative Acts and Gender Constitution: An Essay in Phenomenology and Feminist Theory. Theatre Journal, Vol. 40(4), 519-531. doi: http://www.jstor.org/stable/3207893

Butler, J. (1990). Gender Trouble, London and New York: Routledge.

Butler, J. (1993). Bodies That Matter: On The Discursive Limits of Sex. London and New York: Routledge.

Byrne, A. (2003). Developing a Sociological Model for Researching Women's Self and Social Identity. European Journal of Women's Studies, Vol. 10(4), 443-464. doi: $10.1177 / 13505068030104010$

Carrigan, M. \& Szmigin, I. (2006). 'Mothers of invention': Maternal Empowerment and Convenience Consumption. European Journal of Marketing. Vol. 40(9/10), 1122- 
1142. doi: http://dx.doi.org/10.1108/03090560610681041

Carrigan, M. \& Szmigin, I. (2010). Time, Uncertainty and the Expectancy Experience: An Interpretive Exploration of Consumption and Impending Motherhood. Journal of Marketing Management. Vol. 20(7/8), 771-798. doi: 10.1362/0267257041838755

Catterall, M., Maclaran, P., \& Stevens, L. (2005). Postmodern Paralysis: The Critical Impasse in Feminist Perspectives on Consumers. Journal of Marketing Management, Vol. 21(5-6), 489-504. doi: 10.1362/0267257054307444

Cherlin, A. (2004), The Deinstitutionalization of American Marriage. Journal of Marriage and Family, Vol. 66 (11), 848-861. doi: 10.1111/j.0022-2445.2004.00058.x

Cosivo, D.C. (2004). Amending the Abject Body: Aesthetic Makeovers in Medicine and Culture, Albany: State University of New York Press.

Coskuner-Balli. G. \& Thompson, C.J. (2012). The Status Costs of Subordinate Cultural Capital: At-Home Fathers' Collective Pursuit of Cultural Legitimacy through Capitalizing Consumption Practices. Journal of Consumer Research, Vol. 40(6), 1941). doi:10.1086/668640

Creed, B. (1993). The Monstrous-Feminine: Film, Feminism and Psychoanalysis. London: Routledge.

Eräranta, K., \& Moisander, J. (2011). Psychological Regimes of Truth and Father Identity: Challenges for Work/Life Integration. Organization Studies, Vol. 32(4), 509-526. doi: $10.1177 / 0170840611400293$

Euromonitor (2012). Rise in Single-Person Households Globally Impacts Consumer Spending Patterns. Euromonitor International (17 May 2012).

Fischer, E. \& Arnold, S.J. (1990). More Than A Labor of Love: Gender Roles and Christmas Gift Shopping. Journal of Consumer Research, Vol. 17(3), 333-345. doi: http://www.jstor.org/stable/2626799

Fischer, E. and Gainer, B. (1993). Baby Showers: a Rite of Passage in Transition, in L.McAlister and M.L. Rothchild (eds.), Advances in Consumer Research, Vol.20, Provo, UT: Association for Consumer Research, Pages: 320-324.

Foucault, M. (1975). Discipline and Punish: The Birth of the Prison, New York: Random House.

Fram, E.H. \& Baron, R. (2004). Are Natural Diamond Engagement Rings Forever? International Journal of Retail \& Distribution Management, Vol. 32(7), 340 - 345. doi: 10.1108/09590550410541453

Giddens, A. (1986). The Constitution of Society: Outline of the Theory of Structuration. Cambridge and Malden: Polity Press.

Giddens, A. (1992). The Transformation of Intimacy: Sexuality, Love and Eroticism in Modern Societies, Cambridge, Polity Press.

Goodwin, C. \& Lockshin, L. (1992). The Solo Consumer: Unique Opportunity for the Service Marketer. The Journal of Services Marketing, Vol. 6(3), 27-36. doi: 10.1108/08876049210035908

Gordon, T. (1994). Single Women and Familism: Challenge from the Margins. The European Journal of Women's Studies, Vol. 1(2), 165-182. doi: 10.1177/135050689400100203

Harrison, R.L., Gentry, J.W. \& Commuri, S. (2012). A Grounded Theory of Transition to Involved Parenting: The Role of Household Production and Consumption in the Lives of Single Fathers, in C. Otnes, and L.T. Zayer, (eds.), Gender, Culture and Consumer Behaviour, New York and Hove, Routledge, 337-367. 
Hirschman, E. C. (1993). Ideology in Consumer Research, 1980 and 1990: A Marxist and Feminist Critique. Journal of Consumer Research, Vol. 19(3), 537-555. doi: http://www.jstor.org/stable/2489439

Holden, K. (2007). The Shadow of Marriage: Singleness in England, 1914-60. Manchester Manchester and New York: University Press.

Holstein, J. A. \& Gubrium, J. F. (1995). The Active Interview, Thousand Oaks, CA: Sage.

Houston, R.H. (2004), Other Mothers: Framing the Cybernetic Construction(s) of the Postmodern Family. Consumption, Market and Culture, Vol. 7(3), 191-209. doi: $10.1080 / 1025386042000271333$

Ingraham, C. (1996) 'The Heterosexual Imaginary', in S. Seidman (ed.) Queer Theory/Sociology, Oxford: Blackwell, 168-93.

Jackson, S. \& Scott, S. (2004). Sexual Antinomies in Late Modernity'. Sexualities, Vol. 7(2), 233-248. doi:10.1177/1363460704042166

Kates, S.M. (1999). Making the Ad Perfectly Queer: Marketing "Normality" to the Gay Men's Community? Journal of Advertising, Vol. 28(1), Gender and Multicultural Issues (Spring, 1999), 25-37. doi: http://www.jstor.org/stable/4189098

Kerrane, B Bettany, S \& Hogg, M.K. (2014). Revisiting Contemporary Issues in Family Consumption. Journal of Marketing Management, Vol. 30(15-16), 1527-1532. doi:10.1080/0267257X.2014.937614

Kristeva, J. (1981). Woman's Time. trans. A. Jardine and H. Blake. Signs, Vol. 7(1), 13-35. doi: http://www.jstor.org/stable/3173503

Kristeva, J. (1982) Powers of Horror. An Essay on Abjection. New York: Columbia University Press.

Lacan, J. (1977). The Mirror Stage as Formative of the Function of the I, in Écrits: A Selection, London: Routledge Classics.

Leach, E. R. (1968). The Cereal Packet Norm. The Guardian, 29 January 1968.

Marshall, D., Davis, T., Hogg, M.K., Schneider, T., Petersen, A. (2014). From Overt Provider to Invisible Presence: Discursive Shifts in Advertising Portrayals of the Father in Good Housekeeping, 1950-2010. Journal of Marketing Management, Vol. 30 (15/16), 1654-1679. doi: 10.1080/0267257X.2014.945471

Martin, K.A. (2009). Normalizing Heterosexuality: Mothers' Assumptions, Talk and Strategies with Young Children. American Sociological Review, Vol. 74(2), 190-207. doi: 10.1177/000312240907400202

Mason, J. (1996). Qualitative Researching, London, Thousand Oaks and New Delhi: Sage Publications.

Matcher, E. (2013). Homeward Bound: Why Women are Embracing the New Domesticity, New York: Simon and Schuster.

Moisander, J. \& Valtonen, A. (2006). Qualitative Marketing Research: A Cultural Approach, London: Sage Publications.

Moisander, J., Valtonen, A. \& Hirsto, H. (2009), Personal Interviews in Cultural Consumer Research: Postructuralist challenges. Consumption, Market and Culture. Vol. 12(3), 329-348. doi: 10.1080/10253860903204519

Murphy, P. \& Staples, W. (1979). A Modernized Family Life Cycle. Journal of Consumer Research, Vol. 6(1), 12-22.

O'Malley, L. \& Prothero, A. (2007). Contemporary Families and Consumption, Journal of Consumer Behaviour: Special Issue, Vol. 6(4), 159-163. doi: 10.1002/cb.218

ONS (2012). Measuring National Well-Being: Households and Families, 2012, Office of National Statistics.

Otnes, C. \& Pleck, E.H. (2003). Cinderella Dreams: The Allure of the Lavish Wedding. 
Berkeley: University of California Press.

Otnes, C., Ruth, J.A. \& C.M. Constance (1994). The Pleasure and Pain of Being Close: Men's Mixed Feelings About Participation in Valentine's Day Gift Exchange, in C.T. Allen and D.R. John (eds.), Advances in Consumer Research, Provo, UT : Association for Consumer Research, Vol. 21, 159-164.

Paton, M. (2012). Sin and The Single Mother: The History of Lone Parenthood. The Independent, 16 May 2012.

Patton, M.Q. (1990). Qualitative Evaluation and Research Methods (Second Edition), Newbury Park, London and New Delhi: Sage Publications.

Peñaloza, L. (1994). Crossing Boundaries/drawing Lines: A Look at the Nature of Gender Boundaries and Their Impact on Marketing Research. International Journal of Research in Marketing, 11(4), 359-379. doi:10.1016/0167-8116(94)90012-4

Ramesh, R. (2012). 'Scrounger' Stigma puts Poor People Off Applying for Essential Benefits. The Guardian, 20 November 2012.

Reynolds, J. \& Wetherell, M. (2003). The Discursive Climate of Singleness: The Consequences for Women's Negotiation of a Single Identity. Feminism and Psychology, Vol. 13(4), 489-510. doi: 10.1177/09593535030134014

Rich, A. (1980). Compulsory Heterosexuality and Lesbian Existence. Signs, Vol. 5(4), 631660. doi: http://www.jstor.org/stable/3173834

Roseneil, S. \& Budgeon, S. (2004). Cultures of Intimacy and Care Beyond 'The Family': Personal Life and Social Change in the Early 21st Century. Current Sociology, Vol. 52(2), 135-139. doi: 10.1177/0011392104041798

Rubin, G. (1975). The Traffic in Women: Notes on the 'Political Economy' of Sex, in R.R. Reiter (ed.) Toward an Anthropology of Women, New York: Monthly Review Press, 157-210.

Sandfield, A. \& Percy, C. (2003). Accounting for Single Status: Heterosexism and Ageism in Heterosexual Women's Talk about Marriage. Feminism and Psychology, Vol. 13(4), 475-488. doi: 10.1177/09593535030134013

Schroeder, J., \& Borgerson, J. L. (1998). Marketing Images of Gender: A Visual Analysis. Consumption, Markets and Culture, Vol. 2(2), 161-201. doi: 10.1080/10253866.1998.9670315

Sherry, J.F. (1983). Gift Giving in Anthropological Perspective, Journal of Consumer Research, Vol. 10(9), 157-168.

Stacey, J. (1998), Brave New Families: Stories of Domestic Upheaval in Late-TwentiethCentury America, Berkeley and Los Angeles, University of California Press.

Stein, P.J. (1975). Singlehood: An Alternative to Marriage. The Family Coordinator, Vol. 24(4), 489-503. doi: http://www.jstor.org/stable/583033

The Voice Group (2010), Buying into Motherhood? Problematic Consumption and Ambivalence in Transitional Phases. Consumption, Markets and Culture, Vol. 13(4), 373397._doi:10.1080/10253866.2010.502414

Thompson, C.J. (1996). Caring Consumers: Gendered Consumption Meanings and the Juggling Lifestyle. Journal of Consumer Research. Vol. 22(4), 388-407. doi: http://www.jstor.org/stable/2489789

Thompson, C.J., Locander, W.B. \& Pollio, H.R. (1990). The Lived Meaning of Free Choice: An Existential-Phenomenological Description of Everyday Consumer Experiences of Contemporary Married Women. Journal of Consumer Research, Vol.17 (3), 346-361. doi: http://www.jstor.org/stable/2626800

Thomsen, T.U. \& Sørensen, E.B. (2010). The First Four-wheeled Status Symbol: Pram Consumption as a Vehicle for the Construction of Matherhood Identity. Journal of 
Marketing Management, Vol. 22 (9/10), 907-927. doi: 10.1362/026725706778935619

Tiryakian, E.A. (1981). Sexual Anomie, Social Structure, Societal Change. Social Forces, Vol. 59 (4), Special Issue (June, 1981), 1025-1053. doi: http://www.jstor.org/stable/2577979

Tonkiss, F. (2003). The Ethics of Indifference Community and Solitude in the City. International Journal of Cultural Studies. Vol. 6(3), 297-311. doi: $10.1177 / 13678779030063004$

Tyler, I. (2009). Against Abjection. Feminist Theory, Vol. 10(1), 77-98. doi: $10.1080 / 10253866.2010 .502414$

Wallendorf, M. \& Arnould, E.J. (1991). We Gather Together: Consumption Rituals of Thanksgiving Day. Journal of Consumer Research. Vol. 18 (1), 13-31. doi: http://www.jstor.org/stable/2489481

Wells, W.D. \& Gubar, G. (1966). Life Cycle Concept in Marketing Research. Journal of Marketing Research, Vol. 3(4), 355-63. doi: http://www.jstor.org/stable/3149851

Wilkes, R.E. (1995). Household Life-Cycle Stages, Transitions and Product Expenditures. Journal of Consumer Research, Vol. 22(1), 27-42. doi: http://www.jstor.org/stable/2489698

Wortzel, L.H. (1977). Young Adults: Single People and Single Person Households, in W.D. Perreault Jr. (ed.). Advances in Consumer Research, Vol. 4 Association for Consumer Research, 324-329.

Zajicek, A. M. \& Koski, P. R. (2003). Strategies of Resistance to Stigmatization among White Middle-Class Singles. Sociological Spectrum, Vol. 23(3), 377-403. doi: 10.1080/02732170309203

Zayer, L.T., Sredl,K., Parmentier, M-A. \& Coleman, C. (2012). Consumption and Gender Identity in Popular Media: Discourses of Domesticity, Authenticity, and Sexuality. Consumption, Market and Culture, Vol. 15(4), 333-357. doi: $10.1080 / 10253866.2012 .659437$ 


\section{Biographical Notes}

Ai-Ling is a Lecturer in Marketing at the University of Leicester. She is primarily interested in interpretive consumer research, which draws on cultural and sociological theories to challenge and to explore consumption and marketing issues. Her research explore wide ranging topics such as embodiment, death, self-identity, posthumanism, transformation of intimacy and existential philosophy. Ai-Ling is currently co-habiting with her partner. She spent her 20s and early 30 s as a single professional.

Ming Lim is Lecturer in Marketing and founder of the China Studies Research Alliance (ChiSRA) at the University of Leicester, School of Management. Her research focuses on global branding, consumer culture, technology and science marketing, international marketing and ethics. She has published in the Journal of Macromarketing, Consumption, Markets and Culture, Industrial Marketing Management, Journal of Marketing Management and, most recently, in the Routledge Companion to Digital Marketing (2013) and the WileyBlackwell Encyclopedia of Consumption and Consumer Studies (2014).

Matthew is a Senior Lecturer of Marketing and Consumption and a Senior Fellow of the Higher Education Academy at the University of Leicester. Seemingly unwilling to unlearn his sociological training, Matthew's interests are disparate but mostly involve prodding at issues of marketing culture and ethics that catch his eye. His current research and practice are in the areas of pedagogy and education, morality and invisibility, as well as social enterprise and impact. He is a divorcee and a father of two girls. 